\title{
The INTERPHONE study: design, epidemiological methods, and description of the study population
}

\author{
Elisabeth Cardis · Lesley Richardson - Isabelle Deltour - Bruce Armstrong - Maria Feychting • \\ Christoffer Johansen · Monique Kilkenny · Patricia McKinney • Baruch Modan • \\ Siegal Sadetzki · Joachim Schüz · Anthony Swerdlow • Martine Vrijheid · Anssi Auvinen • \\ Gabriele Berg · Maria Blettner · Joseph Bowman · Julianne Brown · Angela Chetrit · \\ Helle Collatz Christensen · Angus Cook · Sarah Hepworth · Graham Giles · Martine Hours • \\ Ivano Iavarone · Avital Jarus-Hakak · Lars Klaeboe · Daniel Krewski · Susanna Lagorio • \\ Stefan Lönn - Simon Mann · Mary McBride · Kenneth Muir · Louise Nadon · Marie-Elise Parent • \\ Neil Pearce - Tiina Salminen · Minouk Schoemaker $\cdot$ Brigitte Schlehofer · Jack Siemiatycki • \\ Masao Taki $\cdot$ Toru Takebayashi $\cdot$ Tore Tynes $\cdot$ Martie van Tongeren $\cdot$ Paolo Vecchia • \\ Joe Wiart · Alistair Woodward · Naohito Yamaguchi
}

Received: 20 December 2006/ Accepted: 8 June 2007/Published online: 18 July 2007 (C) Springer Science+Business Media B.V. 2007

Abstract The very rapid worldwide increase in mobile
phone use in the last decade has generated considerable
interest in the possible health effects of exposure to radio

Baruch Modan is deceased.

Electronic supplementary material The online version of this article (doi:10.1007/s10654-007-9152-z) contains supplementary material, which is available to authorized users.

E. Cardis $(\bowtie) \cdot$ L. Richardson $\cdot$ I. Deltour .

M. Vrijheid

International Agency for Research on Cancer, 150 Cours Albert

Thomas, 69372 Lyon, Cedex 08, France

e-mail: cardis@iarc.fr

\section{B. Armstrong $\cdot$ J. Brown}

Sydney Cancer Centre and School of Public Health, The University of Sydney, Sydney, Australia

\section{Feychting $\cdot$ S. Lönn}

Institute of Environmental Medicine, Karolinska Institutet, Stockholm, Sweden

\section{Johansen - H. C. Christensen}

Institute of Cancer Epidemiology, Danish Cancer Society, Copenhagen, Denmark

\section{Kilkenny · G. Giles}

Cancer Epidemiology Centre, The Cancer Council Victoria, Melbourne, Australia

\section{P. McKinney $\cdot$ S. Hepworth}

Centre for Epidemiology and Biostatistics, University of Leeds, Leeds, UK frequency (RF) fields. A multinational case-control study, INTERPHONE, was set-up to investigate whether mobile phone use increases the risk of cancer and, more specifi-

B. Modan · S. Sadetzki

Sackler School of Medicine, Tel-Aviv University, Tel Aviv, Israel

S. Sadetzki · A. Chetrit - A. Jarus-Hakak

The Gertner Institute for Epidemiology and Health Policy Research, Chaim Sheba Medical Centre, Tel-Hashomer, Israel

J. Schüz $\cdot$ M. Blettner

Institute of Medical Biostatistics, Epidemiology and Informatics, Johannes Gutenberg-University of Mainz, Mainz, Germany

A. Swerdlow $\cdot$ M. Schoemaker

Institute of Cancer Research, Sutton, UK

A. Auvinen · T. Salminen

Tampere School of Public Health, University of Tampere,

Tampere, Finland

A. Auvinen · T. Salminen

STUK - Radiation and Nuclear Safety Authority, Helsinki, Finland

G. Berg

Department of Epidemiology and International Public Health, Faculty of Public Health, University of Bielefeld, Bielefeld,

Germany

J. Bowman

National Institute for Occupational Safety and Health,

Cincinnati, OH, USA 
cally, whether the RF fields emitted by mobile phones are carcinogenic. The study focused on tumours arising in the tissues most exposed to RF fields from mobile phones: glioma, meningioma, acoustic neurinoma and parotid gland tumours. In addition to a detailed history of mobile phone use, information was collected on a number of known and potential risk factors for these tumours. The study was conducted in 13 countries. Australia, Canada, Denmark, Finland, France, Germany, Israel, Italy, Japan, New Zealand, Norway, Sweden, and the UK using a common core protocol. This paper describes the study design and methods and the main characteristics of the study population. INTERPHONE is the largest case-control study to date investigating risks related to mobile phone use and to other potential risk factors for the tumours of interest and includes 2,765 glioma, 2,425 meningioma, 1,121 acoustic neurinoma, 109 malignant parotid gland tumour cases and 7,658 controls. Particular attention was paid to estimating the amount and direction of potential recall and participation biases and their impact on the study results.

\section{A. Cook}

Department of Public Health, University of Western Australia, Perth, Australia

\section{Hours}

Unité Mixte de Recherche Epidémiologique Transport Travail Environnement INRETS - UCBL - InVS, Université Lyon 1, 69008 Lyon, France

\section{Iavarone}

Department of Environment \& Primary Prevention, Istituto Superiore di Sanità, National Health Institute, Rome, Italy

\section{Klaeboe}

The Cancer Registry of Norway, Oslo, Norway

D. Krewski

McLaughlin Centre for Population Health Risk Assessment, University of Ottawa, Ottawa, Canada

\section{S. Lagorio}

National Centre for Epidemiology, Surveillance and Health Promotion, Istituto Superiore di Sanità, National Health Institute, Rome, Italy

\section{S. Mann}

Health Protection Agency, Centre for Radiation Chemical and Environmental Hazards, Didcot, UK

\section{McBride}

B.C. Cancer Agency, Vancouver, Canada

K. Muir

Division of Epidemiology and Public Health, University of Nottingham, Nottingham, UK

L. Nadon · M.-E. Parent

INRS-Institut Armand-Frappier, Université du Québec, Lavaldes-Rapides, Canada
Keywords Mobile phones - Case-control - Methods · Study design - Cancer - Benign tumours - Brain tumours . Acoustic neurinoma $\cdot$ Parotid gland tumours

$\begin{array}{ll}\text { Abbreviations } \\ \text { CAPI } & \text { Computer assisted personal interview } \\ \text { CT } & \text { Computed tomography } \\ \text { ELF } & \text { Extremely low frequency } \\ \text { EMF } & \text { Electro-magnetic fields } \\ \text { ICNIRP } & \text { International Commission on Non-Ionizing } \\ & \text { Radiation Protection } \\ \text { MRI } & \text { Magnetic resonance imaging } \\ \text { SAR } & \text { Specific absorption rate } \\ \text { SES } & \text { Socio-economic status } \\ \text { UK } & \text { United Kingdom }\end{array}$

N. Pearce

Centre for Public Health Research, Massey University, wellington, New Zealand

B. Schlehofer

Unit of Environmental Epidemiology, German Cancer Research Center, Heidelberg, Germany

J. Siemiatycki

University of Montreal, Montreal, Canada

M. Taki

Department of Electrical and Electronic Engineering, Tokyo Metropolitan University, Tokyo, Japan

T. Takebayashi

Department of Preventive Medicine and Public Health, Keio

University School of Medicine, Tokyo, Japan

T. Tynes

National Institute of Occupational Health, Oslo, Norway

M. van Tongeren

Institute of Occupational Medicine, Edinburgh, UK

P. Vecchia

Department Technology and Health, National Institute of Health, Rome, Italy

J. Wiart

France Telecom R\&D, Issy les Moulineaux, France

A. Woodward

School of Population Health, University of Auckland, Auckland, New Zealand

N. Yamaguchi

Tokyo Women's Medical University, Tokyo, Japan 


\section{Introduction}

It is estimated that there are now over 2 billion mobile phone users in the world, and this number continues to increase [1]. Widespread concern that exposure to RF fields emitted by mobile phones may have an impact on health has accompanied the dramatic increase in use of these phones worldwide [2].

In the late 1990's, several expert groups critically reviewed the available evidence concerning the possible health effects of low-level exposures to RF fields and recommended that research be carried out to determine whether mobile (also called cellular) phones could cause adverse health effects [3-6].

As a result, a feasibility study was carried out in fourteen countries, coordinated by the International Agency for Research on Cancer (IARC) in Lyon. It was concluded that an international study of the relation between mobile phone use and risk of adult head and neck tumours, including brain tumours, would be both feasible and informative [7], while studies of these relatively rare tumours in single countries would generally lack sufficient statistical power. Thus INTERPHONE was initiated as a set of multi-national case-control studies, focusing on four types of tumour: glioma, meningioma, acoustic neurinoma and parotid gland tumours.

Since the beginning of INTERPHONE, the results of a number of other studies on the risk of head and neck tumours in relation to mobile phone use have been published. These include both cohort and case-control studies [8-16]. To date, however, the evidence remains inconclusive about a possible association between mobile phone use and the risk of cancer.

The current paper presents the design, detailed methods, and description of the study population in all the participating centres of INTERPHONE. Some of these centres have already published results [17-38].

Separate papers, based on the full international INTERPHONE study, will address (1) the possible relationship between the risk of these tumours and mobile phone use; (2) the possible relationship between the risk of these tumours and estimated RF exposure from mobile phone use; (3) the contributions to tumour risk of other possible risk factors.

\section{Objectives}

The primary objective of INTERPHONE was to investigate whether mobile phone use increases the risk of tumours and, specifically, whether RF fields emitted by mobile phones are tumourigenic.
Most of the RF absorbed energy from mobile phone use is absorbed in the immediate vicinity of the handset, in a volume of about $5 \mathrm{~cm}^{3}$ in the head. Of this, most is absorbed by the skin, the salivary glands (particularly the parotid gland) and the external ear; only $20-30 \%$ is absorbed by the brain as a whole [39]. In the brain, absorbed energy is highest for glial and meningeal tissue located in the outermost part of the frontal, parietal and temporal lobes on the side of the head where the phone is used [3941]. The tumour types selected for study are those that occur in some of the tissues that receive most of the RF exposure from mobile phone use.

A secondary objective was to evaluate the relation between these tumours and a number of known and potential risk factors, including ionising radiation, occupational exposure to electromagnetic fields and the subject's personal and familial medical history.

\section{Methods}

Sixteen study centres in thirteen countries (Australia; Canada: Montreal, Ottawa, Vancouver; Denmark; Finland; France; Germany; Israel; Italy; Japan; New Zealand; Norway; Sweden; and the UK: North and South) participated in INTERPHONE.

\section{Source population}

In Australia, Canada, France, Germany, Italy, Japan and New Zealand, the source population was restricted to major metropolitan areas where mobile phones were first introduced (Table 1). Major treatment centres for the diseases of interest are concentrated in these areas and most of the population is unlikely to go out of the region for diagnosis and treatment. In all study regions except Paris and Tokyo, it is believed that 90 to $95 \%$ of the cases are diagnosed or treated in the collaborating units (Web Annex Table 1) in the study areas. For practical reasons, limiting the study area to these populations also facilitated face-to-face interviews. In Denmark, Finland, Israel, Norway and Sweden the study was largely nationwide. The UK-South study was restricted to the South East of England, urban and rural, and the UK-North study encompassed both urban areas and sparsely populated rural areas.

All residents in the study regions aged 30 to 59 were eligible for the study; additional eligibility criteria, such as citizenship and proficiency in the local language were imposed in some study centres (Web Annex Table 1). The choice of age-range aimed to maximise the likelihood of exposure. Mobile phone use is a relatively new phenomenon: until the late 1990's mobile phone use was mainly 


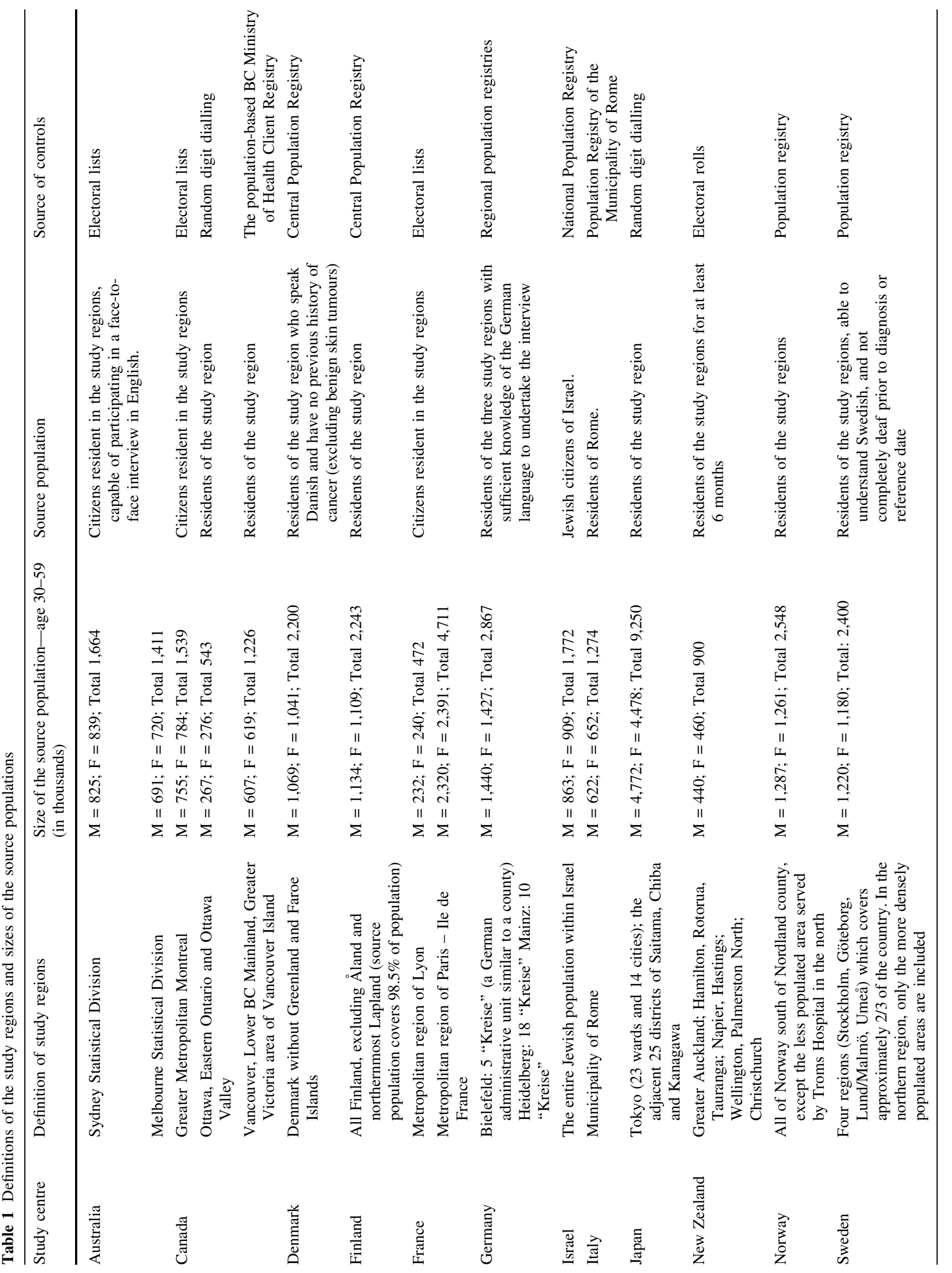


restricted to people in the age range most likely to use the phones for business purposes [7].

Case eligibility and ascertainment

Eligible cases were all residents of the study region diagnosed during the study period with a confirmed first primary glioma, meningioma, or acoustic neurinoma. Eight centres (Australia; Canada-Montreal, Ottawa and Vancouver; Denmark; Israel; Italy; Sweden) also included malignant parotid gland tumours. Because benign parotid gland tumours may be treated in a very large number of institutions, most centres found it logistically difficult to ensure complete ascertainment, and only Canada-Ottawa, Israel and Sweden included them. They will not be discussed in this paper. The ICD codes for the eligible diagnoses are presented in Web Annex Table 2.

All diagnoses were either histologically confirmed or based on unequivocal diagnostic imaging. In Australia and Germany, only histologically confirmed tumours were included. In Denmark cases found to have had any previous cancer (excluding non-melanocytic skin cancer) were excluded.

Each centre established procedures for the rapid ascertainment of cases from participating diagnostic and treatment units, which was particularly important for glioma patients, whose health can deteriorate quickly. Every effort was made to maintain a close relationship with the units to ensure that cases were not missed and that the required authorisations were obtained from treating physicians when necessary. Close monitoring of case ascertainment was essential and all study centres, except Finland and Japan, used one or more secondary source (including medical archives, hospital discharge and billing files, and hospital or regional cancer registries) to improve ascertainment levels. Enrolment of cases through secondary sources often implied longer delays in case ascertainment and consequently lower participation.

\section{Control eligibility and selection}

Controls were randomly selected from the source population. The sampling frame depended on the local situation (Table 1). The study design called for controls to be individually- or frequency-matched to cases, with the number of controls varying according to the tumour type: 1 control per case for brain tumours; 2 for acoustic neurinoma; and 3 for parotid gland tumours. In Germany, two controls were selected for each brain tumour case. Controls were matched on year of birth (within 5-year categories), sex and study region.

Controls were individually matched to cases in CanadaOttawa, Vancouver; France, Israel, Japan, New Zealand 
and UK-North. In the other centres, individual matching was conducted post hoc, with cases being assigned controls chosen to have been interviewed as close as possible in time to the case, from among those who fit the matching criteria.

Approach to subjects and informed consent

All cases for whom physician authorisation for contact had been obtained and all controls were initially informed about the study and asked to participate. The procedures varied between centres (Web Annex Table 3), depending on the requirements of local Ethics Review Boards. In seven centres, the cases were initially approached by the treating physician or a nurse for consent to be included in the study. In other study centres approaches included: active case ascertainment by the study staff followed by physician authorisation to contact each case directly; blanket approval to contact all eligible cases; or a mix of the two. In all centres participants provided signed informed consent.

\section{Collection of information on individual study subjects}

Whenever possible, consenting subjects were interviewed face-to-face by trained interviewers using a computer-assisted personal interview (CAPI) questionnaire. Only Finland used a paper version of the questionnaire. In exceptional cases, telephone interviews were conducted with difficult-to-reach subjects. If subjects became too tired or confused to complete the interview in one session a second appointment was arranged; a partner or other family member could assist in the interview. When the study subject had died or was too ill to participate, a proxy respondent was interviewed where this was possible and permitted by ethics committees. In Australia and New Zealand an abbreviated questionnaire was used for proxy interviews. Controls who refused to participate in the study were asked, whenever possible, to complete a short nonrespondent questionnaire in all centres, except in Denmark and UK-South, in order to evaluate whether they differed from participating controls. A small number of cases in some centres also completed the non-respondent questionnaire. Detailed results of analyses of the non-respondent questionnaires will be published separately.

The study questionnaire covered demographic factors, mobile phone use (detailed below), use of other wireless communication devices including cordless DECT telephones, occupational exposures to EMF and other potential confounders or risk factors for the diseases of interest (including exposure to ionising radiation, smoking and the subject's personal and familial medical history). Specific questions on exposure to loud noise and hearing loss were asked of acoustic neurinoma cases and their controls (and of all controls in centres using frequency matching).

\section{History of mobile phone use}

Detailed questions were asked of regular mobile phone users, defined as those with an average of at least one call per week for a period of 6 months or more, concerning their history of phone use. A paper calendar was handed to the subject. Together, the respondent and interviewer attempted to identify each phone used (aided by show cards with pictures of hundreds of models of mobile phones that were compiled and updated during the course of the study) and to reconstruct the time period during which it was used. This provided the subject with a visual record of the phone history when responding to the subsequent detailed questions.

For each phone, detailed questions were asked about the initial pattern of use, including network operator and average number and duration of calls, and any subsequent changes in use patterns. Questions were also asked about the proportion of time the phones were used in urban, suburban or rural settings, while stationary or moving in a vehicle, how often the antenna was extended, and whether headsets or hands-free kits were used, as these factors may modify the RF output power of the phones. The side of the head on which the phone was usually held (i.e. the laterality of phone use) and the handedness (left or right-handed) of the subject were recorded.

\section{Validation studies}

Validation studies were conducted to assess the accuracy of subjects' recall of their history of mobile phone use. Shortterm recall was assessed in volunteer subjects using either software modified phones or network operators' records in eleven countries [42]. Validation of medium- to long-term recall of phone use in comparison with network operator records was possible in three countries (Australia, Canada and Italy) for cases and controls, while validation of shortterm recall was possible for some subjects in Denmark, Israel, and Sweden. Detailed methods and results of these studies will be published separately.

\section{Information on socio-economic status (SES) and other socio-demographic factors}

Attained level of education was used as a proxy for SES. As education systems and attained levels do not have a direct correspondence from one country to another, country-specific options for responses were used and recoded into one of two schemes as indicated in Web Annex Table 6. The exception was Germany, where an algorithm 
developed by the German Epidemiological Association was applied [43]. Marital status and, where appropriate, education level of the spouse were also recorded.

\section{Diagnostic information}

Detailed diagnostic information was obtained from medical records for all cases interviewed and for non-interviewed cases in most study centres. This information included anatomical location and side of the tumour and histopathology, including whether benign, malignant or of uncertain behaviour (Web Annex Table 2).

\section{Localisation of brain tumours}

Since intracranial RF energy deposition from mobile phones is non-uniform, with most of the energy absorbed in the vicinity of the phone, the probable location of the origin of the brain tumours was identified so that the RF "exposure" at that location could be evaluated. Neuro-radiologists in each centre reviewed radiological images (MRI and CT scans) or records and recorded tumour location on a generic 3-dimensional grid map of the human head, made up of cubes $1 \mathrm{~cm}^{3}$ in size, which was developed for the purpose. The details of this methodology will be published separately.

\section{Data quality assurance}

The CAPI questionnaire included many checks: the sequence of questions was constrained with little opportunity to skip questions and automatic range and consistency checks were incorporated. After completion of the interviews, routine checks were performed on the data from all centres both locally and centrally. Inconsistencies and ambiguities were identified and resolved wherever possible.

\section{Assessment of exposure from mobile phones}

The study used two main approaches to characterising exposure from mobile phones. The first depended only on the history of use derived from questionnaire responses and the second attempted to evaluate the amount of RF energy absorbed in different areas of the brain.

In both approaches, exposure was calculated up to a given reference date, which was set to the date of the diagnosis of the case in each matched set. Evaluation of RF energy absorption required the localisation of the tumour, which was defined crudely in terms of the side of the head, or lobe of the brain, or more precisely, from the exact location of the tumour on the 3-dimensional grid. Exposure for each control was estimated at the location of the tumour of his/her matched case.

\section{Exposure derived from mobile phone history}

Indices of exposure, including cumulative call time, average call duration and cumulative number of calls, overall and within specific time-windows, with and without use of hands-free devices, were computed using the detailed information reported by regular users.

\section{Absorbed RF energy}

The amount and distribution of RF energy absorption in the head vary according to a number of factors, including the type of telephone and network (frequency and type of transmission: digital or analogue, continuous or discontinuous, use of power control), as well as the subject's patterns of use of the phone. We developed and validated a model to estimate exposure, assessing the relative importance of the different factors and testing the adequacy of the proposed approach. The algorithm combines questionnaire responses with information on tumour location, the distribution of the specific absorption rate (SAR) of RF in the head and factors that modify the amount of RF energy emitted by the phone. This will be the subject of a separate paper.

\section{Missing data}

To avoid exclusion of subjects with missing responses to questions about mobile phone use (which might be more frequent in cases and long-term users and hence lead to a bias), rules were developed for the imputation of missing data. Hierarchical rules were defined a priori, and the same imputation procedure was applied to each pertinent instance. For example, if the number or duration of calls made during a specific time period was missing, but the subject provided information for adjacent time periods, the value was imputed as the average of the two adjacent periods. When this information was not available, the imputed value was the median use of all other users, in the same period and region $[44,45]$.

\section{Analytical methods}

The primary goals of the international analyses are to assess whether use of mobile phones and exposure to RF fields increase the risk of selected tumours. In devising analytic strategies, the following features must be considered:

- Exposure (absorbed RF energy from the phone) is highly localised;

- The prevalence of phone use has increased rapidly during the course of the study; 
- If there is risk, most previous studies imply that it would be of low magnitude on the relative risk scale;

- The mechanism for an effect, if there is one, is unknown; the relevant exposure metric is therefore uncertain.

The main analyses will be based on conditional logistic regression for matched sets. This simplifies the assignment of the reference date, laterality and "tumour location" for the controls, which are important when analysing the effects of an exposure that is very localised. In addition, for an exposure that increased rapidly during the course of the study, and considering that subjects' recall of their past exposures may be influenced by their current and recent use patterns, the matching ensures that cases and controls have been interviewed relatively closely in time.

\section{Results}

Case ascertainment

The median delay between date of diagnosis and interview for glioma cases was 3 months, ranging from less than 2 months in three centres to 14 months in Norway where initial difficulties in the identification of cases were only overcome at a later stage (Table 2). Delays for meningioma were similar overall (not shown), although the median in several centres was a little longer than for glioma. Delays for acoustic neurinoma and malignant parotid gland tumours tended to be longer-overall median 6 months and 9 months respectively: because of their generally good prognosis, retrospective case ascertainment over a period of one year was allowed for these tumour types to increase the sample size.

The proportion of low to high-grade glioma cases ascertained was quite consistent across most centres where this could be determined: $66 \%$ high-grade and $28 \%$ lowgrade, with $6 \%$ unknown overall. Overall $1 \%$ of the meningiomas were malignant and 5\% of unknown behaviour. This was consistent across all study centres (not shown).

\section{Control recruitment}

Table 3 shows the distribution of intervals between the dates of interview of glioma cases and their matched controls. The overall median interval was 2 months, but varied by centre, ranging up to 6 months in Japan and 8 months in Israel. $72 \%$ of the controls were interviewed within 6 months of their matched cases. The proportions

Table 2 Distribution of delays between diagnosis and interview-glioma cases only

\begin{tabular}{|c|c|c|c|c|c|c|}
\hline \multirow[t]{3}{*}{ Study Centre } & \multirow[t]{3}{*}{ Number of cases } & \multicolumn{5}{|c|}{ Delay between diagnosis and interview (months) } \\
\hline & & \multirow{2}{*}{ Median } & \multicolumn{4}{|c|}{ Percentage of cases } \\
\hline & & & -1 to 1 & 1 to 3 & 3 to 6 & More than 6 \\
\hline Australia & 301 & 4 & 1 & 41 & 30 & 29 \\
\hline \multicolumn{7}{|l|}{ Canada } \\
\hline Montreal & 65 & 7 & 0 & 3 & 37 & 60 \\
\hline Ottawa & 25 & 8 & 8 & 16 & 8 & 68 \\
\hline Vancouver & 80 & 5 & 0 & 1 & 60 & 39 \\
\hline Denmark & 181 & 2 & 15 & 50 & 19 & 16 \\
\hline Finland & 178 & 0 & 75 & 16 & 4 & 4 \\
\hline France & 94 & 2 & 32 & 30 & 14 & 24 \\
\hline Germany & 256 & 0 & 69 & 6 & 5 & 20 \\
\hline Israel & 180 & 3 & 19 & 27 & 18 & 36 \\
\hline Italy & 118 & 6 & 15 & 15 & 19 & 50 \\
\hline Japan & 60 & 1 & 42 & 40 & 12 & 7 \\
\hline New Zealand & 84 & 4 & 0 & 27 & 58 & 14 \\
\hline Norway & 180 & 14 & 16 & 2 & 7 & 75 \\
\hline Sweden & 227 & 3 & 13 & 42 & 30 & 15 \\
\hline \multicolumn{7}{|l|}{ UK } \\
\hline North & 429 & 2 & 5 & 62 & 20 & 13 \\
\hline South & 307 & 4 & 2 & 27 & 34 & 37 \\
\hline Total & 2,765 & 3 & 19 & 31 & 22 & 27 \\
\hline
\end{tabular}


Table 3 Distribution of interval between the dates of interview of controls and of cases to which they are matched—glioma cases only

\begin{tabular}{|c|c|c|c|c|c|c|c|}
\hline \multirow[t]{3}{*}{ Study Centre } & \multirow{3}{*}{$\begin{array}{l}\text { Number of } \\
\text { cases }^{\mathrm{a}}\end{array}$} & \multicolumn{6}{|c|}{ Interval between interview of controls and date of interview of the cases to which they are matched (months) } \\
\hline & & \multirow[t]{2}{*}{ Median } & \multicolumn{5}{|c|}{ Percentage of matched sets } \\
\hline & & & $\begin{array}{l}\text { More than } 6 \text { months } \\
\text { before case }\end{array}$ & $\begin{array}{l}1 \text { to } 6 \text { months } \\
\text { before case }\end{array}$ & $\begin{array}{l}\text { Within } 1 \text { month } \\
\text { of case }\end{array}$ & $\begin{array}{l}1 \text { to } 6 \text { months } \\
\text { after case }\end{array}$ & $\begin{array}{l}\text { More than } 6 \text { months } \\
\text { after case }\end{array}$ \\
\hline Australia & 297 & 0 & 11 & 10 & 35 & 28 & 16 \\
\hline \multicolumn{8}{|l|}{ Canada } \\
\hline Montreal & 65 & 0 & 9 & 20 & 46 & 25 & 0 \\
\hline Ottawa $^{\text {b }}$ & 25 & 1 & 4 & 24 & 24 & 40 & 8 \\
\hline Vancouver $^{\mathrm{b}}$ & 80 & 3 & 1 & 6 & 17 & 51 & 24 \\
\hline Denmark & 179 & 0 & 1 & 11 & 51 & 30 & 7 \\
\hline Finland & 177 & 1 & 2 & 12 & 40 & 36 & 11 \\
\hline France $^{b}$ & 94 & 4 & 1 & 0 & 6 & 60 & 33 \\
\hline Germany & 256 & 3 & 11 & 10 & 9 & 48 & 22 \\
\hline Israel $^{\mathrm{b}}$ & 180 & 8 & 2 & 6 & 3 & 30 & 59 \\
\hline Italy & 118 & 5 & 16 & 15 & 4 & 24 & 41 \\
\hline Japan $^{\text {b }}$ & 60 & 6 & 0 & 2 & 2 & 47 & 50 \\
\hline New Zealand ${ }^{\mathrm{b}}$ & 83 & 5 & 4 & 3 & 8 & 44 & 40 \\
\hline Norway & 154 & 0 & 16 & 22 & 23 & 19 & 20 \\
\hline Sweden & 222 & 1 & 3 & 14 & 31 & 34 & 18 \\
\hline \multicolumn{8}{|l|}{ UK } \\
\hline North $^{\mathrm{b}}$ & 421 & 3 & 0 & 0 & 7 & 76 & 17 \\
\hline South & 299 & 1 & 7 & 17 & 31 & 24 & 21 \\
\hline Total & 2,710 & 2 & 6 & 10 & 21 & 41 & 23 \\
\hline
\end{tabular}

${ }^{a}$ Only cases with matched controls are included

b Study centre with individual matching of controls to cases

were respectively $6 \%$ and $23 \%$ for interviews more than 6 months before, and more than 6 months after their matched cases. The former was very low $(<=4 \%)$ in the study centres where individual matching was used.

\section{Participation}

Case participation varied considerably by tumour type and by centre (Table 4). The overall participation was $65 \%$ for glioma cases (ranging from $37 \%$ to $92 \%$ ), $78 \%$ for meningioma (ranging from $57 \%$ to $92 \%$ ), $82 \%$ for acoustic neurinoma (ranging from $70 \%$ to $100 \%$ ) and $75 \%$ for malignant parotid gland tumours (with a wide range based on very small numbers).

Participation was calculated as the proportion of all eligible ascertained cases that were interviewed. The denominator includes cases whose physician denied authorisation to contact them: $5 \%$ of glioma, $2 \%$ of meningioma and acoustic neurinoma and $9 \%$ of malignant parotid gland tumour cases. This proportion was relatively small for most centres and in eight centres there were none at all.
There was little difference between centres in participation of glioma cases according to grade of tumour: $67 \%$ overall for cases with high-grade tumours and $71 \%$ for cases with low-grade tumours.

Overall participation amongst controls was 53\% (Table 4) but showed large variation across centres, ranging from $35 \%$ to $74 \%$. Eight of the study centres achieved control participation of $60 \%$ or higher. The major reasons for non-participation were refusal $(64 \%$ of non-participants) and inability to contact $(27 \%)$.

Amongst cases there was very little difference in participation by age except in women with glioma, where participation in the older age group was noticeably lower. Amongst controls there were slightly higher participation rates amongst women than men (Table 5).

Type and location of interview

The vast majority of interviews (94\% for glioma cases and $95 \%$ for controls) were conducted face-to-face; the remaining interviews were conducted by telephone (Table 6). In most centres the proportion of face-to-face 
Table 4 Distribution of all cases and controls ascertained and proportion interviewed by study centre

\begin{tabular}{|c|c|c|c|c|c|c|c|c|c|c|}
\hline \multirow[t]{2}{*}{ Study centre } & \multicolumn{2}{|l|}{ Glioma } & \multicolumn{2}{|c|}{ Meningioma } & \multicolumn{2}{|c|}{ Acoustic neurinoma } & \multicolumn{2}{|c|}{$\begin{array}{l}\text { Malignant parotid gland } \\
\text { tumours }\end{array}$} & \multicolumn{2}{|l|}{ Controls } \\
\hline & $\begin{array}{l}\text { No. } \\
\text { ascertained }\end{array}$ & $\begin{array}{l}\text { No. }(\%) \\
\text { Interviewed }\end{array}$ & $\begin{array}{l}\text { No. } \\
\text { ascertained }\end{array}$ & $\begin{array}{l}\text { No. }(\%) \\
\text { interviewed }\end{array}$ & $\begin{array}{l}\text { No. } \\
\text { ascertained }\end{array}$ & $\begin{array}{l}\text { No. }(\%) \\
\text { interviewed }\end{array}$ & $\begin{array}{l}\text { No. } \\
\text { ascertained }\end{array}$ & $\begin{array}{l}\text { No. }(\%) \\
\text { interviewed }\end{array}$ & $\begin{array}{l}\text { No. from } \\
\text { sampling } \\
\text { frame }\end{array}$ & $\begin{array}{l}\text { No. }(\%) \\
\text { interviewed }\end{array}$ \\
\hline Australia & 536 & $301(56)$ & 413 & $255(62)$ & 179 & $127(71)$ & 21 & $7(33)$ & 1,608 & $669(42)$ \\
\hline \multicolumn{11}{|l|}{ Canada } \\
\hline Montreal & 101 & $65(64)$ & 71 & $48(68)$ & 41 & $33(80)$ & 13 & $9(69)$ & 391 & $234(60)$ \\
\hline Ottawa & 38 & $25(66)$ & 18 & $15(83)$ & 21 & $17(81)$ & 6 & $6(100)$ & 259 & $180(69)$ \\
\hline Vancouver & 134 & $80(61)$ & 45 & $31(69)$ & 41 & $34(83)$ & 19 & $13(68)$ & 680 & $239(35)$ \\
\hline Denmark & 248 & $181(73)$ & 155 & $121(81)$ & 73 & $71(97)$ & 15 & $15(100)$ & 1,277 & $662(52)$ \\
\hline Finland & 211 & $178(84)$ & 252 & $231(92)$ & 87 & $76(87)$ & $-{ }^{\mathrm{a}}$ & - & 1,337 & $559(42)$ \\
\hline France & 155 & $94(61)$ & 190 & $148(78)$ & 140 & $111(79)$ & - & - & 639 & $472(74)$ \\
\hline Germany & 312 & $256(82)$ & 275 & $250(91)$ & 76 & $67(88)$ & - & - & 1,869 & $1190(64)$ \\
\hline Israel & 206 & $180(87)$ & 390 & $350(90)$ & 78 & $72(92)$ & 20 & $19(95)$ & 911 & $599(66)$ \\
\hline Italy & 128 & $118(92)$ & 124 & $110(89)$ & 30 & $30(100)$ & 11 & $11(100)$ & 486 & $340(70)$ \\
\hline Japan & 90 & $60(67)$ & 102 & $82(80)$ & 82 & $69(84)$ & - & - & 568 & $287(51)$ \\
\hline New Zealand & 132 & $84(69)$ & 72 & $54(75)$ & 21 & $20(95)$ & - & - & 350 & $172(49)$ \\
\hline Norway & 236 & $180(76)$ & 191 & $148(77)$ & 51 & $38(75)$ & 21 & $11(52)$ & 404 & $278(69)$ \\
\hline Sweden & 298 & 227 (76) & 205 & $184(90)$ & 107 & $102(95)$ & 20 & $18(90)$ & 617 & 407 (66) \\
\hline \multicolumn{11}{|l|}{ UK } \\
\hline North & 628 & $429(68)$ & 222 & $180(81)$ & 116 & $102(88)$ & - & - & 1,747 & 788 (45) \\
\hline South & 848 & 307 (37) & 390 & $221(57)$ & 218 & $152(70)$ & - & - & 1,211 & $582(48)$ \\
\hline Total & 4,301 & $2,765(65)$ & 3,115 & $2,425(78)$ & 1,361 & $1,121(82)$ & 146 & $109(75)$ & 14,354 & $7,658(53)$ \\
\hline
\end{tabular}

${ }^{a}$ Parotid gland tumours were not included in these centres

Table 5 Participation rates amongst cases and controls by age and sex, all study centres combined

\begin{tabular}{|c|c|c|c|c|c|c|c|c|c|c|}
\hline \multicolumn{11}{|c|}{ Number of cases ascertained and controls selected (\% interviewed) } \\
\hline \multirow[t]{2}{*}{ Age } & \multicolumn{2}{|l|}{ Glioma } & \multicolumn{2}{|c|}{ Meningioma } & \multicolumn{2}{|c|}{ Acoustic neurinoma } & \multicolumn{2}{|c|}{ Malignant parotid gland tumours } & \multicolumn{2}{|l|}{ Controls } \\
\hline & Women & Men & Women & Men & Women & Men & Women & Men & Women & Men \\
\hline $30-39^{\mathrm{a}}$ & $398(70)$ & $565(67)$ & $313(74)$ & $109(79)$ & $139(86)$ & $156(81)$ & $21(81)$ & $14(79)$ & $1,601(54)$ & $1,663(48)$ \\
\hline $40-49$ & $487(70)$ & $750(68)$ & $797(78)$ & $251(76)$ & $231(81)$ & 227 (80) & $23(83)$ & $21(62)$ & $2,333(58)$ & $2,100(51)$ \\
\hline $50-59^{\mathrm{a}}$ & $816(58)$ & $1,285(62)$ & $1,239(80)$ & $406(75)$ & $325(83)$ & $283(83)$ & $26(73)$ & $41(73)$ & $3,573(55)$ & $3,084(52)$ \\
\hline Overall & $1,701(64)$ & $2,600(64)$ & 2,349 (79) & $766(76)$ & $695(83)$ & $666(82)$ & $70(79)$ & $76(71)$ & $7,507(56)$ & $6,847(51)$ \\
\hline
\end{tabular}

\footnotetext{
${ }^{a}$ Note that controls may have been younger than 30 or older than 59 when matched to cases in the lowest or highest age groups
}

interviews was over $90 \%$. However, in Italy and Norway respectively $39 \%$ and $48 \%$ of case interviews and $65 \%$ and $46 \%$ of control interviews were conducted by telephone. The patterns of telephone interviews amongst cases with the other tumour types were very similar (not shown).

The overall proportion of proxy respondents for glioma cases was $13 \%$. This varied considerably across centres, from $2 \%$ to over $40 \%$ (Table 6). A small proportion of interviews was conducted with the study subject accompanied by another person. The proportion of proxy inter- views was less than $2 \%$ for meningioma and even less for acoustic neurinoma and parotid gland cases. As would be expected, there were virtually no proxy respondents amongst the controls except in New Zealand where proxy interviews were conducted for the controls matched to cases who could not be interviewed themselves.

Overall, $60 \%$ of the face-to-face interviews with glioma cases were conducted at home, 33\% in hospital, and 7\% elsewhere (Web Annex Table 4). This varied greatly: in some centres, nearly all interviews were conducted at 
Table 6 Distributions of interviews by mode of interview and interviewee, for glioma cases and all controls

\begin{tabular}{|c|c|c|c|c|c|c|c|c|c|c|}
\hline \multirow[t]{4}{*}{ Study centre } & \multicolumn{2}{|c|}{ Total number of interviews } & \multicolumn{8}{|c|}{ Percentage of interviews that were } \\
\hline & & \multirow[b]{3}{*}{ Controls } & \multicolumn{4}{|c|}{ Mode of interview } & \multicolumn{4}{|c|}{ Interviewee } \\
\hline & \multirow[b]{2}{*}{ Cases } & & Face-to & -face & Teleph & one & \multicolumn{2}{|c|}{ Subject alone or with another person } & \multicolumn{2}{|l|}{ Proxy } \\
\hline & & & Cases & Controls & Cases & Controls & Cases & Controls & Cases & Controls \\
\hline Australia & 301 & 669 & 99 & 98 & 1 & 2 & 86 & 100 & 14 & 0 \\
\hline \multicolumn{11}{|l|}{ Canada } \\
\hline Montreal & 65 & 234 & 95 & 94 & 5 & 6 & 63 & 98 & 37 & 2 \\
\hline Ottawa & 25 & 180 & 92 & 100 & 8 & 0 & 84 & 100 & 16 & 0 \\
\hline Vancouver & 80 & 239 & 100 & 100 & 0 & 0 & 98 & 100 & 3 & 0 \\
\hline Denmark & 181 & 662 & 100 & 100 & 0 & 0 & 94 & 100 & 6 & 0 \\
\hline Finland & 178 & 559 & 99 & 99 & 1 & 1 & 97 & 100 & 3 & 0 \\
\hline France & 94 & 472 & 97 & 88 & 3 & 12 & 89 & 100 & 11 & 0 \\
\hline Germany & 256 & 1190 & 100 & 100 & 0 & 0 & 90 & 100 & 10 & 0 \\
\hline Israel & 180 & 599 & 99 & 99 & 1 & 1 & 81 & 100 & 19 & 0 \\
\hline Italy & 118 & 340 & 61 & 35 & 39 & 65 & 56 & 95 & 44 & 5 \\
\hline Japan & 60 & 287 & 100 & 100 & 0 & 0 & 98 & 100 & 2 & 0 \\
\hline New Zealand & 84 & 172 & 100 & 100 & 0 & 0 & 79 & 88 & 20 & 12 \\
\hline Norway & 180 & 278 & 52 & 54 & 48 & 46 & 69 & 100 & 31 & 0 \\
\hline Sweden & 227 & 407 & 94 & 94 & 6 & 6 & 93 & 100 & 7 & 0 \\
\hline \multicolumn{11}{|l|}{ UK } \\
\hline North & 429 & 788 & 100 & 100 & 0 & 0 & 92 & 100 & 8 & 0 \\
\hline South & 307 & 582 & 100 & 100 & 0 & 0 & 95 & 100 & 5 & 0 \\
\hline Total & 2,765 & 7,658 & 94 & 95 & 6 & 5 & 87 & 99 & 13 & 1 \\
\hline
\end{tabular}

home; in others, nearly all were in hospital. The distribution of interview location was similar for meningioma and acoustic neurinoma cases (not shown). In contrast, $7 \%$ of control interviews took place in hospital (mainly in Finland and, to a lesser extent in Norway and Sweden, where study subjects were invited to treatment institutions for interview), $70 \%$ in the subject's home and $22 \%$ elsewhere (Web Annex Table 4).

\section{Quality of interviews}

After an interview had been completed the interviewer recorded his or her impression of the reliability of information on a 5-point scale, overall and for each specific section. The percentage of subjects judged by the interviewer to be unresponsive or uncooperative overall was very low for both cases and controls (1.8 and 1.2\% respectively), ranging by centre from 0 to $5.6 \%$ among glioma cases and up to $4.7 \%$ among controls. The percentages of cases and controls who were mobile phone users and were judged by the interviewer to have had little or no difficulty in remembering past phone use were 80,86 , 91 and 94\%, respectively, among glioma, meningioma, acoustic neurinoma and parotid gland tumour cases, and 91\% among controls (not shown).

Interviews were conducted by 230 different interviewers, the number ranging from 2 in Canada-Montreal to 39 in Denmark. About 35\% of the interviewers conducted less than 20 interviews and $25 \%$ of the interviewers conducted fewer than 10 , mostly with cases. While $84 \%$ of the subjects were interviewed by interviewers who had a balanced workload between cases and controls, the workload in three centres was particularly unbalanced (Web Annex Table 5).

\section{Subjects available for analyses}

Table 7 shows the number of cases and controls available for analysis, as well as the total number of matched sets by tumour type. Overall there were 2,765 glioma cases, 2,425 meningioma cases, 1,121 acoustic neurinoma cases, 109 malignant parotid gland tumour cases and 7,658 controls available for analysis. A total of 55 glioma, 15 meningioma, 17 acoustic neurinoma and 2 parotid gland tumour cases were excluded from matched analyses due to a lack of suitable controls. Conversely, 196 interviewed controls could not be matched to any cases. 
Table 7 Number of cases and controls available for analysis and number of matched case-control sets, by tumour type and study centre

\begin{tabular}{|c|c|c|c|c|c|c|c|c|c|c|c|c|}
\hline & \multicolumn{3}{|c|}{ Glioma } & \multicolumn{3}{|c|}{ Meningioma } & \multicolumn{3}{|c|}{ Acoustic neurinoma } & \multicolumn{3}{|c|}{$\begin{array}{l}\text { Malignant parotid gland } \\
\text { tumours }\end{array}$} \\
\hline & $\begin{array}{l}\text { No. } \\
\text { cases }\end{array}$ & $\begin{array}{l}\text { No. } \\
\text { controls }\end{array}$ & $\begin{array}{l}\text { Matched } \\
\text { sets }^{\mathrm{a}}\end{array}$ & $\begin{array}{l}\text { No. } \\
\text { cases }\end{array}$ & $\begin{array}{l}\text { No. } \\
\text { controls }\end{array}$ & $\begin{array}{l}\text { Matched } \\
\text { sets }\end{array}$ & $\begin{array}{l}\text { No. } \\
\text { cases }\end{array}$ & $\begin{array}{l}\text { No. } \\
\text { controls }\end{array}$ & $\begin{array}{l}\text { Matched } \\
\text { sets }\end{array}$ & $\begin{array}{l}\text { No. } \\
\text { cases }\end{array}$ & $\begin{array}{l}\text { No. } \\
\text { controls }\end{array}$ & $\begin{array}{l}\text { Matched } \\
\text { sets }\end{array}$ \\
\hline Australia & 301 & 669 & 297 & 255 & 669 & 253 & 127 & 669 & 127 & 7 & 669 & 7 \\
\hline \multicolumn{13}{|l|}{ Canada } \\
\hline Montreal & 65 & 234 & 65 & 48 & 234 & 48 & 33 & 234 & 33 & 9 & 234 & 9 \\
\hline Ottawa & 25 & 180 & 25 & 15 & 180 & 15 & 17 & 34 & 17 & 6 & 180 & 6 \\
\hline Vancouver & 80 & 239 & 80 & 31 & 239 & 31 & 34 & 72 & 34 & 13 & 239 & 13 \\
\hline Denmark & 181 & 662 & 179 & 121 & 662 & 124 & 71 & 425 & 70 & 15 & 662 & 15 \\
\hline Finland & 178 & 559 & 177 & 231 & 559 & 231 & 76 & 559 & 75 & $-{ }^{b}$ & & \\
\hline France & 94 & 472 & 94 & 148 & 472 & 144 & 111 & 221 & 107 & - & & \\
\hline Germany & 256 & 1190 & 256 & 250 & 1190 & 250 & 67 & 144 & 67 & - & & \\
\hline Israel & 180 & 599 & 180 & 350 & 599 & 350 & 72 & 264 & 72 & 19 & 599 & 19 \\
\hline Italy & 118 & 340 & 118 & 110 & 340 & 110 & 30 & 68 & 30 & 11 & 340 & 11 \\
\hline Japan & 60 & 287 & 60 & 82 & 287 & 82 & 69 & 287 & 69 & - & & \\
\hline New Zealand & 84 & 172 & 83 & 54 & 172 & 52 & 20 & 32 & 17 & - & & \\
\hline Norway & 180 & 278 & 154 & 148 & 278 & 143 & 38 & 278 & 38 & 11 & 278 & 11 \\
\hline Sweden & 227 & 407 & 222 & 184 & 407 & 184 & 102 & 361 & 102 & 18 & 251 & 16 \\
\hline \multicolumn{13}{|l|}{ UK } \\
\hline North & 429 & 788 & 421 & 180 & 788 & 173 & 102 & 185 & 94 & - & & \\
\hline South & 307 & 582 & 299 & 221 & 582 & 220 & 152 & 582 & 152 & - & & \\
\hline Total & 2,765 & 7,658 & 2,710 & 2,425 & 7,658 & 2,410 & 1,121 & 4,415 & 1,104 & 109 & 3,452 & 107 \\
\hline
\end{tabular}

a The case to control ratio is one to one for glioma and meningioma, one to two for acoustic neurinoma and one to three for parotid gland tumours. Note that in Germany two matched controls were interviewed for each case of glioma and meningioma

b -Parotid gland tumours were not included in theses centres

\section{Missing data}

About $10 \%$ of glioma cases and about $5 \%$ of the other cases and of controls had some missing data concerning their history of mobile phone use (Table 8). The percentage varied across centres (ranging from 2.7 to $23.7 \%$ among glioma cases and 0.7 to $13.8 \%$ among controls).

Socio-demographic factors

The proportion of subjects in the lowest educational level was somewhat higher for cases than controls in several centres (Web Annex Table 6). There were little differences in marital status between cases and controls for all types of tumour. Women were less likely than men to be married (not shown).

\section{Discussion}

INTERPHONE is the largest case-control study of glioma, meningioma, acoustic neurinoma and parotid gland tumours to date. It was set-up to evaluate possible associations between RF exposure from mobile telephones and risk of these tumours. It focuses on mobile phone use, by far the largest source of exposure to RF fields in the general population. Comparing exposures from mobile phones with the wide array of existing RF devices is complicated because they depend, inter alia, on the output power, the frequency of the field emitted and proximity to the source. Sources at a distance, such as radio-TV transmitters and base stations, imply low levels of exposure [46]. Sources operated close to the human body entail the highest levels of exposure [47]. Other wireless applications such as cordless phones or wireless Internet (WLAN) systems are now very common; however, their peak output power is below the level of typical mobile phones. Cordless telephones have an average output power of the order of $10 \mathrm{~mW}$ for DECT and less for other technologies [46], compared to about $120 \mathrm{~mW}$ for mobile phones operating in GSM 900 for example.

In addition to providing information concerning risks related to mobile phone use, INTERPHONE provides the largest case-control source of data on other potential risk factors for the tumours of interest including medical and 
Table 8 Proportion of subjects in each study centre for whom missing mobile phone use data were imputed-by case-control status

\begin{tabular}{|c|c|c|c|c|c|c|c|c|c|c|}
\hline & \multicolumn{2}{|c|}{ Glioma } & \multicolumn{2}{|c|}{ Meningioma } & \multicolumn{2}{|c|}{ Acoustic neurinoma } & \multicolumn{2}{|c|}{$\begin{array}{l}\text { Malignant parotid } \\
\text { gland tumours }\end{array}$} & \multicolumn{2}{|l|}{ Controls } \\
\hline & $\begin{array}{l}\text { No. } \\
\text { cases }\end{array}$ & $\begin{array}{l}\% \text { With } \\
\text { imputed values }\end{array}$ & $\begin{array}{l}\text { No. } \\
\text { cases }\end{array}$ & $\begin{array}{l}\% \text { With } \\
\text { imputed values }\end{array}$ & $\begin{array}{l}\text { No. } \\
\text { cases }\end{array}$ & $\begin{array}{l}\% \text { With } \\
\text { imputed values }\end{array}$ & $\begin{array}{l}\text { No. } \\
\text { cases }\end{array}$ & $\begin{array}{l}\% \text { With } \\
\text { imputed values }\end{array}$ & $\begin{array}{l}\text { No. } \\
\text { controls }\end{array}$ & $\begin{array}{l}\% \text { With } \\
\text { imputed values }\end{array}$ \\
\hline Australia & 301 & 16.6 & 255 & 2.0 & 127 & 2.4 & 7 & 0.0 & 669 & 4.9 \\
\hline \multicolumn{11}{|l|}{ Canada } \\
\hline Montreal & 65 & 12.3 & 48 & 2.1 & 33 & 0.0 & 9 & 0.0 & 234 & 4.3 \\
\hline Ottawa & 25 & 4.0 & 15 & 0.0 & 17 & 5.9 & 6 & 0.0 & 180 & 1.1 \\
\hline Vancouver & 80 & 3.8 & 31 & 9.7 & 34 & 0.0 & 13 & 0.0 & 239 & 4.6 \\
\hline Denmark & 181 & 8.8 & 121 & 9.6 & 71 & 5.6 & 15 & 6.7 & 662 & 6.3 \\
\hline Finland & 178 & 12.4 & 231 & 10.8 & 76 & 5.3 & $-^{\mathrm{a}}$ & & 559 & 13.8 \\
\hline France & 94 & 9.6 & 148 & 2.8 & 111 & 3.6 & - & & 472 & 4.7 \\
\hline Germany & 256 & 2.7 & 250 & 1.6 & 67 & 0.0 & - & & 1,190 & 1.7 \\
\hline Israel & 180 & 10.6 & 350 & 4.0 & 72 & 5.6 & 19 & 10.5 & 599 & 6.7 \\
\hline Italy & 118 & 23.7 & 110 & 5.5 & 30 & 10.0 & 11 & 0.0 & 340 & 9.7 \\
\hline Japan & 60 & 6.7 & 82 & 1.2 & 69 & 5.8 & - & & 287 & 0.7 \\
\hline New Zealand & 84 & 6.0 & 54 & 0.0 & 20 & 0.0 & - & & 172 & 1.7 \\
\hline Norway & 180 & 9.4 & 148 & 6.1 & 38 & 7.9 & 11 & 0.0 & 278 & 5.8 \\
\hline Sweden & 227 & 14.5 & 184 & 13.0 & 102 & 12.7 & 18 & 11.1 & 407 & 7.6 \\
\hline \multicolumn{11}{|l|}{ UK } \\
\hline North & 429 & 7.9 & 180 & 2.2 & 102 & 2.0 & - & & 788 & 3.4 \\
\hline South & 307 & 12.1 & 221 & 2.7 & 152 & 5.3 & & & 582 & 6.4 \\
\hline Total & 2,765 & 10.6 & 2,425 & 4.9 & 1,121 & 4.7 & 109 & 4.6 & 7,658 & 5.3 \\
\hline
\end{tabular}

a -Parotid gland tumours were not included in these study centres

occupational exposure to EMF and to ionising radiation and medical history of subjects and their families.

To the extent possible, we standardised the design, procedures and materials across study centres. Some methodological variation across centres was unavoidable, however, in regard to approach to cases and controls, type of interview and mode of interview. The varying constraints of ethical committees influenced the methods of recruitment of cases and controls. In some centres quite a large proportion of cases was ascertained late through secondary sources. Because of this, a number of cases (particularly glioma) had died or were too ill to be interviewed and proxy respondents had to be found. A substantial proportion of interviews, particularly for controls, was conducted by phone to increase participation in some centres.

Case-control studies such as INTERPHONE are prone to various possible sources of error. These include possible selection bias related to non-participation amongst cases and controls; random and differential error in recall of mobile phone use; differences between cases and controls in timing of interviews in a period of dramatic increase of mobile phone use; and confounding by other potential risk factors for these diseases.

\section{Selection bias}

The INTERPHONE study is no exception to the apparently inexorable decline in participation rates amongst controls selected from the general population for epidemiological studies [48]. The source population is younger than in many other cancer studies and at an age when response rates tend to be lower. The youngest men proved particularly difficult to recruit. Another factor influencing the participation of controls is the difficulty of finding a sampling frame with sufficiently accurate, up-to-date and complete information, which resulted in large numbers of subjects who could not be traced or could not be contacted using the methods authorised by ethics committees.

The possibility that participation among controls might be selective with respect to phone use was of concern, given the low participation rate $(53 \%)$. Mobile phone users could be over-represented among non-participating subjects as they may be more difficult to trace (fewer with listed telephone numbers for land-lines) or too busy to participate; this could lead to overestimation of the true OR. Alternatively, we have some evidence from the nonrespondent questionnaires-which were completed by $57 \%$ of controls who refused to participate and may not be 
representative of all non-participants in the study-that non mobile phone users may be more likely to refuse to participate, perhaps in the mistaken belief that non-users are of no interest to the study [49]. Such a bias could artificially increase the proportion of users among interviewed controls and reduce the likelihood of finding an effect should it exist. As ordained by local ethics committees, the presentation of the study differed somewhat by centre. We estimate that $41 \%$ of all controls were recruited in centres that used an approach in letters and information material that explicitly indicated that the primary objective concerned mobile phones, $46 \%$ were recruited in centres that mentioned mobile phones, without highlighting them, and $13 \%$ in the three centres that made no explicit mention of mobile phones. Thus there is a potential for differential participation between users and non-users and between users by level of use. The impact of a possible selection bias with respect to controls has been evaluated in a simulation study and shown to be potentially important [50]. Thus, it will have to be taken into account in interpreting the INTERPHONE results. In particular, analyses will be conducted by level of participation and by mode of presentation of the study.

Selection bias with regard to severity of illness may also arise in cases, particularly glioma cases. For example, as would be expected from the poor prognosis and strong impact on communication skills, the participation of glioma cases $(65 \%)$ was less than that of patients with meningioma, acoustic neurinoma and malignant parotid gland tumours (78, 82 and $75 \%$ respectively). If $\mathrm{RF}$ exposure were related to the severity and prognosis of cancer, differential participation due to severe illness, early death or cognitive impairment could lead to bias. Despite considerable effort to ensure rapid ascertainment to avoid these difficulties, late ascertainment of a proportion of cases because of logistic reasons and, in some countries difficulties in complying with the requirements of ethics committees, resulted in lower participation than expected. Comparison of response by grade of tumour for gliomas, however, shows no major difference across study centres with different delays between diagnosis and interview. The possibility of severity or survival bias will nevertheless have to be considered when interpreting results.

\section{Recall error}

Self-reports of historical mobile phone use may be prone to substantial error. If such errors occur randomly, they usually bias risk estimates towards the null (no effect). They also increase the uncertainty of risk estimates, making it more likely that real associations are not detected. Results of short-term validation studies with volunteers indicate that recall of phone use is subject to moderate systematic error, but substantial random error: a substantial proportion of subjects markedly over- or under-estimated their mobile phone use [42].

Cases may spend time after the diagnosis of their tumour trying to understand why they have developed this disease, which might introduce a differential bias (sometimes referred to as rumination bias) in comparison with controls in recall of the amount and side of phone use. In addition, some of the patients with glioma might have recalled their phone use less accurately because of severe illness or cognitive impairment. Information about possible differences in recall of amount of use between cases and controls was obtained from retrospective validation studies. Analyses are underway and will be taken into account in the interpretation of results. The results of these analyses will be published separately.

Analyses of the INTERPHONE data will include various approaches to examining the potential for recall bias related to mobile phone use.

\section{Other sources of bias}

Possible confounding effects of region, age and sex will be taken into account systematically by the matching of cases and controls. Indeed, the mean ages of cases and controls are very close (glioma cases and controls 47.3 years; meningioma cases and controls 49.3 years; acoustic neurinoma 47.5 and 47.7 years respectively for cases and controls; parotid gland tumour cases and controls 46.3 years).

Because SES may well be correlated with mobile phone usage and with brain cancer risk [51], our primary indicator of SES, education status, will be included as a confounder in the analyses.

A priori, we do not have strong grounds for believing that other possible causes of the tumours studied, such as family history of brain tumour, past medical radiation exposure, smoking history and occupations in jobs with potential for ionising and non-ionising radiation exposure, would be related to mobile phone use. Nonetheless, the possibility of confounding by these factors will be examined empirically and they will be included in risk models where their inclusion results in a change in the ORs for the mobile phone use variables of $10 \%$ or more [52].

The fact that controls tended to be interviewed later than cases may also be a source of bias: because of the dramatic increase of mobile phone use during the study period, subjects interviewed later are more likely to have been mobile phone users. This will be handled by the matching, by truncating the exposure history of controls at the reference date, and, where appropriate, by adjustment of analyses for dates of interview and by analyses restricted to cases and matched controls interviewed close in time. 
Symptoms of the disease could affect the use of mobile phones. Thus the year before diagnosis will not be included in the exposure period, and control exposure time will be truncated accordingly. For some tumours, however, early symptoms may appear much earlier. This will need to be considered carefully for acoustic neurinoma patients, as the early symptoms comprise hearing loss, tinnitus or buzzing sounds in the ear, which could lead patients to use mobile phones less frequently or to change the side of use.

There is also concern about the possibility of bias due to differences between cases and controls and between short term and long-term users in the extent of missing information and imputations for missing values were therefore conducted. Sensitivity analyses will be conducted excluding subjects with imputations, telephone and proxy interviews, and study subjects who were judged by the interviewer to be uncooperative or to remember their phone use poorly.

Differential assignment of cases and controls to interviewers in some centres and the use of many interviewers who conducted few interviews may be another potential source of bias. Sensitivity analyses will be conducted excluding interviewers with fewer than 20 interviews and those who interviewed nearly exclusively cases or controls.

Finally, despite the fact that INTERPHONE was jointly planned and based on a common core protocol, there was some heterogeneity in the methods used. Sensitivity analyses will be conducted excluding, in turn, different study centers. Additional analyses of patterns of results across study centres are planned to evaluate, in particular, the impact of the way the study was presented (whether a study of mobile phone use or a more general study) and of the participation levels among cases and controls. These will be helpful in addressing the potential for bias that might affect the overall findings.

\section{Conclusions}

Large, carefully conducted multi-centric international studies are an important source of information for the elucidation of the possible impact of mobile phone usage on cancer risk. This paper describes the complex methods used as well as the methodological hurdles that we have encountered. Particular attention was paid to errors and biases resulting from selection and non-participation of eligible subjects and from reporting of mobile phone usage. Different types of sub-studies were conducted to inform the analysis and interpretation of results.

Acknowledgements The authors would like to thank Emilie Combalot, Monika Moissonnier; Marie Sanchez and Hélène Tardy of IARC for their meticulous attention to detail in preparing the inter- national data set for analysis and cheerful willingness to look at it all every which way. Lucia Ardoino was invaluable in putting together the show cards and assisting Paolo Vecchia in the Exposure Assessment committee. Kanako Wake and her colleagues at the National Institute of Information and Communications Technology (NICT) also contributed to the work of the Exposure Assessment committee. James Doughty performed miracles implementing the CAPI in several languages and several versions, assisted by Roger Parslow. We would also like to thank Jan Ivar Martinsen for additional programming work. Liz Findlay contributed a great deal to the development of materials and training of interviewers. We would also like to thank all the research assistants and interviewers in the different study centres for their efforts to ensure that the study was carried out with care and with due consideration for the participants. The Australian team would like to acknowledge the support given to study design and implementation by Associate Professor Michael Besser and Professor Andrew Kaye and the substantial contributions neurosurgery, neuropathology and other clinical staff made to conduct of the study; and to thank the fieldwork staff in Melbourne-Georgina Marr, Tracey McPhail, Fiona Phillips, Hayley Shaw, Yvonne Torn-Broers; and Sydney-Matthew Carroll, Sally Dunlop, Virginia MacDonald and Elizabeth Willows - and the many interviewers for their hard work, and the NSW and Victorian Cancer Registries for aiding case identification. The Canada-Montréal team acknowledges the diligent work of fieldwork staff including Marie-Claire Goulet, Sylvie Plante, Sally Campbell and the interviewer team. We are grateful to Dr. Rafael Glikstein and Dr. Geneviève Matte who contributed to the tumour localisation efforts. The Canada-Vancouver centre wishes to acknowledge the work carried out by Dr. Alison Pope, Patricia Nelson, Nelson Ha, Dr. Kaushik Bhagat and the interviewer team. The Finnish centre thank Dr J J Jääskeläinen (Helsinki University Hospital), Dr S Valtonen (Turku University Hospital), Professor J Koivukangas (Oulu University Hospital), Professor M Vapalahti (Kuopio University Hospital), Dr T Kuurne (Tampere University Hospital) and Professor R Sankila (Finnish Cancer Registry). We would like to thank the French fieldwork team, Mary-Pierre Herrscher, Fatima Lamri, Agnès Boidart, Hélène Gire, Juliette Krassilchik, Judith Lenti, Delphine Maillac, Frédérique Sonnet, Flore Taguiev, Julie Frantz, France Castay, Florian Gay, for their excellent work; Prof. Doyon (Paris) and Dr. Marc Hermier (Lyon) who were actively involved in the both the development of the methodology for tumour localisation and the review of all cases in France; all the hospital services who assisted us in the ascertainment of cases: Lyon Centre Hospitalier Lyon-Sud (Prof. Dubreuil), Hôpital Neurologique Pierre Wertheimer (Prof. Trouillas, Dr. Honnorat, Prof. Confavreux, Dr. Achiti, Prof. Fisher, Prof. Vallée, Dr.s Farsi and Mahla, Prof. Bret, Dr. Ricci, Prof. Sindou, Prof. Deruty), Hôpital d'instruction des Armées Desgenettes (Dr. Felten), Centre Léon Bérard (Dr. Frappaz), Clinique du Tonkin (Dr. de Garassus, Dr. Brudon); Paris-Hôpital de La Pitié Salpétrière (Prof.s Fohanno and Cornu, Dr. Lopes, Dr. Bloch, Dr. Capelle, Dr. Duffau, Prof. Delattre, Dr. Sanson, Prof. Hauw, Prof. Poirier, Dr. Marsault), Hôpital Foch (Prof. Visot, Dr. Gaillard, Dr. Dupuy, Prof. Chabolle), Hôpital Beaujon (Prof. Sterkers, Dr. Bouccara), Hôpital Lariboisière (Prof. Georges, Dr. Blanquet Dr. Koot, Prof. Tran Ba Huy), Hôpital Ste Anne (Prof. Roux, Dr. Turak), Fondation Rothschild (Dr. Mouder, Dr. Daguet, Dr. Piekarski), Hôpital d'Instruction des Armées du Val de Grâce (Prof. Bequet, Prof. Renard, Prof. Desgeorges) Hôpital St Joseph (Dr. Gauthier), Centre Hospitalier intercommunal de Poissy-St Germain en Laye (Dr. Cambon), Centre Hospitalier Sud-Francilien (Dr. Serre), Centre Hospitalier de Meaux (Dr. Améri); Marseille-Hôpital de la Timone (Prof. Peragut, Dr. Regis), as well as all those in the Departments of medical information and all the hospital personnel, particularly the secretaries and the staff in the medical archives, whose assistance proved essential to the success of the project. The German group wish to thank their team members Dr Eva Böhler, 
Marianne Brömmel, Stephanie Estel, Iris Hettinger, Melanie Hetzer, Katharina Kunna-Grass, Klaus Schlaefer, Dr Jürgen Wahrendorf and Anna Wilms and all the interviewers for their skilful work. They thank the clinical Interphone team for their support and collaboration (Bielefeld: Prof. Falk Oppel (Neurosurgical clinic), Dr Uwe Dietrich (Neuroradiology), Dr Volkmar Hans (Neuropathology), Heidelberg: Prof. Andreas Unterberg, Prof. Stefan Kunze, Dr Karsten Geletneky (Neurosurgical clinic), Prof. Klaus Sator, Dr Jochen Fiebach (Neuroradiology), Prof. Marika Kiessling (Neuropathology), Mannheim: Prof. Peter Schmiedek, Dr Jochen Tüttenberg (Neurosurgical clinic), Prof. Christoph Groden, Dino Podlesek (Neuroradiology), Prof. Uwe Bleyl, Dr Rainer Grobholz (Neuropathology), Mainz: Prof. Axel Perneczky, Prof. Nico Hopf, Dr Dorothee Koch (Neurosurgical clinic), Prof. Wolf Mann, Prof. Nickalaos Marangos (ENT clinic), Dr Wibke Müller-Forell (Neuroradiology), Prof. Hans Hilmar Göbel (Neuropathology)). The Italian team included Enrica Barbieri, Rita Basili, Caterina Carnovale Scalzo, Edvina Galiè, Massimo Lucibello, Rossella Rossi and Cristiano Tesei. We thank Prof. Bruno Jandolo (IFO Regina Elena) who co-ordinated the Rome hospital network, and the following neurosurgeons, ENT-surgeons, neuroradiologists, pathologists, and health managers: Prof. Umberto Agrillo, Dr. Amalia Allocca Dr. Mostafà Amini, Dr. Cinzia Bernardi, Dr. M. Bonamini, Dr. Loredana Bove, Prof. Luigi Bozzao, Dr. Alessandro Bozzao, Dr. Mario Braga, Dr. Fabrizio Breccia, Dr. Velia Bruno, Dr. Andrea Brunori, Dr. Antonella Buffoni, Prof. Arnaldo Capelli, Prof. Giampaolo Cantore, Prof. Natale Cantucci, Dr. Emanuela Caroli, Prof. Cosimo Cassano, Dr. Alessandra Castelnuovo, Dr. Costanza Cavuto, Prof. Lucia Cecconi, Dr. Franco Cerquetani, Dr. Carla Colacecchi, Dr. Antonio Comberiati, Dr. Valeria D'Alfonso, Dr. Giovanni De Angelis, Dr. Luca de Campora, Prof. Roberto Delfini, Dr. Carlo Della Rocca, Prof. Marco De Vincentiis, Dr. Domenica Di Stefano, Prof. Stefano Esposito, Prof. Alfredo Fabiano, Dr. Francesco Federico, Prof. Luigi Ferrante, Dr. Anna Rita Fetoni, Dr. Letizia Feudi, Prof. Roberto Filipo, Prof. Roberto Floris, Prof. Felice Giangaspero, Dr. Renato Gigli, Dr. Marco Giordano, Prof. Gianfranco Gualdi, Prof. G. Guglielmi, Dr. Massimo Iachetti, Prof. Giorgio Iannetti, Dr. Maria Rosaria Limiti, Prof. Giulio Maira, Dr. Valentina Manciocco, Dr. Annunziato Mangiola, Dr. Ferdinando Marandino, Dr. Luisa Marangoni, Prof. Pasquale Marano, Dr. Stefano Martini, Prof. Maria Enrica Martini Neri, Dr. Luciano Mastronardi, Dr. Arianna Mattioni, Prof. Maurizio Maurizi, Dr. Maria Concetta Mazzeo, Dr. Giuseppe Natali, Dr. Gaetano Nostro, Prof. Emanuele Occhipinti, Prof. Antonio Orlacchio, Prof. Augusto Orlandi, Prof. Fabrizio Ottaviani, Dr. Salvatore Passafaro, Dr. Francesco Saverio Pastore, Dr. Laura Pennesi, Dr. Claudio Maria Pianura, Prof. Roberto Pisa, Dr. Chimene Pistolesi, Prof. Giuseppe Poladas, Dr. Siavash Rahimi, Dr. Emanuela Rastelli, Prof. Antonio Ricci, Dr. P. Rigotti, Dr. Massimo Rimatori, Dr. Rossana Romani, Prof. Giuseppe Santeusanio, Dr. Sergio Santilli, Dr. Marco Scarpinati, Dr. Lauro Sciannamea, Prof. Luigi Sinibaldi, Prof. Giuseppe Spriano, Dr. Maurizio Giovanni Vigili, Dr. Antonello Vidiri, Dr. Massimo Volpe. We are grateful to Dr. Francesco Forastiere, Daniela D'Ippoliti and Stefania Palange (Epidemiologic Unit ASL RME) for their support in case ascertainment and control selection. We acknowledge the collaboration of the Italian mobile phone network operators in providing us with traffic data for the exposure validation studies. The Swedish centre thanks the Swedish Regional Cancer Registries and the hospital staff; especially the following key persons at the hospitals: Dr J Boethius, Dr O Flodmark, Prof. I Langmoen, Dr A Lilja, Dr T Mathiesen, Dr I Olsson Lindblom and Dr H Stibler (Karolinska University Hospital), Dr J Lycke, Dr A Michanek and Prof. L Pellettieri (Sahlgrenska University Hospital), Prof. T Möller and Prof. L Salford (Lund University Hospital), Dr T Bergenheim, Dr L Damber, Prof. R Henriksson and Dr B Malmer (Umeå University Hospital). Prof. Swerdlow's team in the UK-South included D. Hogben, A. Butlin, J Owens, A Hart, R. Knight, C. Parsley, M. Pelerin, K. Sampson and M Swanwick. The UK South centre thanks Prof. H Møller, Mr B Plewa and Mr S Richards from the Thames Cancer Registry and the following neuropathologists, neurosurgeons, neuro-oncologists, clinical oncologists, neurologists, other health care staff, administrators and secretaries for the help they provided: Mr DG Hardy, Mr PJ Kilpatrick, Mr R Macfarlane (Addenbrooke's Hospital); Ms M Cronin, Ms T Foster, Ms S Furey, Dr M G Glaser, Ms F Jones, Mr ND Mendoza, Prof. ES Newlands, Mr KS O'Neill, Mr D Peterson, Ms F Taylor, Prof. J van Dellon (Charing Cross Hospital); Dr JJ Bending (Eastbourne District Hospital); Mr PR Bullock, Mr C Chandler, Mr B Chitnavis, Mr L Doey, Mr RW Gullan, Prof. CE Polkey, Mr R Selway, Mr MM Sharr, Ms L Smith, Prof. AJ Strong, Mr N Thomas (King's College Hospital); Dr GM Sadler (Maidstone Hospital); Dr S Short (Mount Vernon Hospital); Prof. S Brandner, Mr G Brookes, Mr AD Cheesman, Professor MJ Gleeson, Miss JP Grieve, Mr WJ Harkness, Dr R Kapoor, Mr ND Kitchen, Mrs T Pearce, Mr MP Powell, Dr J Rees, Prof. F Scaravilli, Prof. DT Thomas, Mr LD Watkins (National Hospital for Neurology and Neurosurgery); Mr AR Aspoas, Mr S Bavetta, Mr J C Benjamin, Mr KM David, Mr JR Pollock, Dr E Sims (Oldchurch Hospital); Mrs J Armstrong, Mr J Akinwunmi, Mr G Critchley, Mr L Gunasekera, Mr C Hardwidge, Mr JS Norris, Dr PE Rose, Mr PH Walter, Mr PJ Ward, Dr M Wilkins (Princess Royal Hospital); Prof. TZ Aziz, Prof. D Kerr, Mr PJ Teddy (Radcliffe Infirmary); Ms M Allen, Ms T Dale, Mr R Bradford, Dr C Collis, Prof. AP Dhillon, Mr NL Dorward, Ms D Farraday-Browne, Dr DJ McLaughlin, Mr RS Maurice-Williams, Dr K Pigott, Ms B Reynolds, Ms C Shah, Mr C Shieff, Dr EM Wilson (Royal Free Hospital); Mr F Afshar, Mr HE Ellamushi, Prof. PM Richardson, Mr HI Sabin, Mr J Wadley (Royal London Hospital); Professor M Brada, Dr FH Saran, Mrs D Traish, Mr D Guerrero (Royal Marsden Hospital); Dr S Whitaker (Royal Surrey County Hospital); Dr PN Plowman (St. Bartholomew's Hospital); Mrs Carole Bramwell, Prof. A Bell, Mr F Johnston, Mr H Marsh, Mr A Martin, Mr PS Minhas, Miss A Moore, Mr S Stapleton, Dr S Wilson (St. George's Hospital); Dr RP Beaney (St Thomas' Hospital). The UKNorth centre wishes to acknowledge the support of the following neuropathologists, neuroradiologists, neurosurgeons, neuro-oncologists, clinical oncologists, neurologists, specialist nurses and administrators based in hospitals located in Scotland (Mr Barlow, Professor I Bone, Ms J Brown, Mr J Crowther, Miss R Dolan, Mr Dunn, Mr MO Fitzpatrick, Mrs M Fraser, Dr R Grant, Dr A Gregor, Mr Johnstone, Mr Lyndsay, Mrs S Macnamara, Miss J Mair, Mr R Mills, Miss Myles, Mr B O’Reilly, Mr V Papanastassiou, Professor R Rampling, Mr Russell, Mr D Sim, Mr P Statham, Mr Steers, Mr Taylor, Prof. Teasdale, Professor I Whittle), west Midlands (Dr JM Anderson, Dr Barbour, Dr CR Barraclough, Dr P Bennett, Dr HG Boddie, Mr Brind, Dr Carey, Mr M Choksey, Mr M Christie, Dr RN Corston, Professor GS Cruickshank, Dr A Detta, Mr P Dias, Dr SJ Ellis, Mr G Flint, Dr DA Francis, Mr AH Grubneac, Mr SP Harland, Dr C Hawkins, Dr T Heafield, Dr RC Hughes, Dr DG Jamieson, Dr A Logan, Mr CHA Meyer, Mrs R Mitchell, Professor K Morrison, Dr P Newman, Dr D Nicholl, Dr S Nightingale, Dr HS Pall, Mr JR Ponsford, Dr A Shehu, Mr Singh, Dr JA Spillane, Mr P Stanworth, Dr B Summers, Mr AR Walsh, Mr J Wasserberg, Professor AC Williams, Dr J Winer, Mr S Zygmunt), Trent (Dr RJ Abbott, Ms Sheila Adams, Mr Ashpole, Mr RDE Battersby, Professor L Blumhardt, Mr P Byrne, Miss M Cartmil, Dr SC Coley, Dr PCritchley, Dr Faraj, Dr A Gibson, Dr P Griffiths, Dr R Grunwald, Dr TJ Hodgson, Mr DT Hope, Dr S Howell, Dr D Jefferson, Mr D Jellinek, Dr N Jordan, Mr A Kemeny, Dr MC Lawden, Professor J Lowe, Dr N Messios, Ms Kirsty Pardoe, Dr S Price, Dr IF Pye, Mr M Radatz, Mr I Robson, Dr K Robinson, Dr C Romanowski, Dr G Sawle, Dr B Sharrock, Professor P Shaw, Dr C Smith, Dr W Temperley, Dr G Venables, Mr B White, Mr AM Whiteley, Dr Wills) and West Yorkshire (Dr Al-Din, Dr D Ash, Dr J Bamford, Dr M Bond, Dr G Bonsor, Dr L Bridges, Dr B Carey, Dr Chakrabarty, Mr P Chumas, Dr D Dafalla, Dr H Ford, Dr Gerrard, Dr Goulding, Dr J Howe, Dr S Jamieson, Dr Johnson, Dr Louizou, Mr 
P Marks, Dr M Nelson, Dr S Omer, Mr N Phillips, Mr S Ross, Dr I Rothwell, Dr H Spokes, Dr J Straiton, Mr G Towns, Nr A Tyagi, Mr P Vanhille, Dr M Busby).This study was conducted with funding from the European Fifth Framework Program, "Quality of Life and Management of Living Resources" (contract QLK4-CT-1999901563) and the International Union against Cancer (UICC). The UICC received funds for this purpose from the Mobile Manufacturers' Forum and GSM Association. Provision of funds to the INTERPHONE study investigators via the UICC was governed by agreements that guaranteed INTERPHONE's complete scientific independence. The terms of these agreements are publicly available at http://www.iarc.fr/ENG/ Units/RCAd.html/. The Australian centre was supported by the National Health and Medical Research Council (EME Grant 219129); Bruce Armstrong is supported by a University of Sydney Medical Foundation Program Grant and Julianne Brown by an Australian Postgraduate Award. The Cancer Council NSW and The Cancer Council Victoria provided most of the infrastructure for the project in Australia. The Canada-Montréal data collection was funded by a grant from the Canadian Institutes of Health Research (project MOP42525). Dr. Siemiatycki had salary support from the Canada Research Chair programme. Dr. Parent had salary support from the Fonds de recherche en santé du Québec. The other Canadian centres were supported by a university-industry partnership grant from the Canadian Institutes of Health Research (CIHR), the latter including partial support from the Canadian Wireless Telecommunications Association. The CIHR university-industry partnerships program also includes provisions that ensure complete scientific independence of the investigators. D. Krewski is the NSERC/SSHRC/ McLaughlin Chair in Population Health Risk Assessment at the University of Ottawa. The Danish centre was supported by the Danish Cancer Society and the Finnish centre by the Emil Aaltonen Foundation and the Academy of Finland. Additional funding for the study in France was provided by l'Association pour la Recherche sur le Cancer (ARC: Contrat No. 5142) and three network operators (Orange, SFR, Bouygues Télécom). The funds provided by the operators represented $5 \%$ of the total cost of the French study and were governed by contracts guaranteeing the complete scientific independence of the investigators. In Germany additional funds were received from the German Mobile Phone Research Program (Deutsches Mobilfunkforschungsprogramm) of the German Federal Ministry for the Environment, Nuclear Safety, and Nature Protection; the Ministry for the Environment and Traffic of the state of Baden-Württemberg; the Ministry for the Environment of the state of North Rhine-Westphalia; the MAIFOR Program (Mainzer Forschungsforderungsprogramm) of the University of Mainz. The study conducted in Japan was fully funded by the Ministry of Internal Affairs and Communications of Japan. In New Zealand, funding was provided by the Health Research Council, Hawkes Bay Medical Research Foundation and the Cancer Society of New Zealand. The Swedish centre was also supported by the Swedish Research Council and the Swedish Cancer Society. Additional funding for the UK-North \& UK-South studies was received from the Mobile Telecommunications, Health and Research (MTHR) program and the UK-North study received funding from the Health and Safety Executive, the Department of Health, the UK Network Operators (O2, Orange, T-Mobile, Vodafone, '3') and the Scottish Executive.

\section{References}

1. Mobiletracker. Mobiletracker Accessed: 13 June 2006. Available from: URL:http://www.mobiletracker.net/archives/2006/06/13/2billion-gsm

2. World Health Organization. WHO 2006 Research Agenda for Radio Frequency Fields. Geneva: World Health Organisation; 2006.
3. International Commission on Non-Ionizing Radiation Protection 1997 (ICNIRP). Non-Thermal Effects of RF Electromagnetic Fields Proceedings of the International Seminar on Biological Effects of RF Electromagnetic Fields and Related Health Risks. 20 November 1996. Munich, Germany.

4. McKinlay A. Possible health effects related to the use of radiotelephones - recommendations of a European Commission Expert Group. Radiol Protect Bull 1997;1879-16.

5. Repacholi M. Low-level exposure to radiofrequency electromagnetic fields: health effects and research needs. Bioelectromagnetics 1998;191-19.

6. Royal Society of Canada. A Review of the Potential Health Effects of Radiofrequency Fields from Wireless Telecommunications Devices. Ottawa: Royal Society of Canada; 1999.

7. Cardis E, Kilkenny M. International case-conrol study of adult brain, head and neck tumours: results of the feasibility study. Rad Prot Dos 1999;83:179-83.

8. Muscat JE, Malkin MG, Thompson S, Shore RE, Stellman SD, McRee D, et al Handheld cellular telephone use and risk of brain cancer. JAMA 2000;284(23):3001-7.

9. Schuz J, Jacobsen R, Olsen JH, Boice JD, Jr., McLaughlin JK, Johansen C. Cellular telephone use and cancer risk: update of a nationwide Danish cohort. J Natl Cancer Inst 2006;98(23):170713.

10. Inskip PD, Tarone RE, Hatch EE, Wilcosky TC, Shapiro WR, Selker RG, et al. Cellular-telephone use and brain tumors. N Engl J Med 2001;344(2):79-86.

11. Johansen C, Boice J Jr., McLaughlin J, Olsen J. Cellular telephones and cancer - a nationwide cohort study in Denmark. J Natl Cancer Inst 2001;93(3):203-7.

12. Auvinen A, Hietanen M, Luukkonen R, Koskela RS. Brain tumors and salivary gland cancers among cellular telephone users. Epidemiology 2002;13(3):356-9.

13. Muscat JE, Malkin MG, Shore RE, Thompson S, Neugut AI, Stellman SD, et al. Handheld cellular telephones and risk of acoustic neuroma. Neurology 2002;58(8):1304-6.

14. Warren HG, Prevatt AA, Daly KA, Antonelli PJ. Cellular telephone use and risk of intratemporal facial nerve tumor. Laryngoscope 2003;113(4):663-7.

15. Hardell L, Carlberg M, Hansson MK. Case-control study on cellular and cordless telephones and the risk for acoustic neuroma or meningioma in patients diagnosed 2000-2003. Neuroepidemiology 2005;25(3):120-8.

16. Hardell L, Carlberg M, Hansson Mild K. Pooled analysis of two case-control studies on use of cellular and cordless telephones and the risk for malignant brain tumours diagnosed in 19972003. Int Arch Occup Environ Health 2006;79(8):630-9.

17. Christensen HC, Schuz J, Kosteljanetz M, Poulsen HS, Thomsen J, Johansen C. Cellular telephone use and risk of acoustic neuroma. Am J Epidemiol 2004;159(3):277-83.

18. Lonn S, Ahlbom A, Hall P, Feychting M. Mobile phone use and the risk of acoustic neuroma. Epidemiology 2004;15(6):653-9.

19. Lonn S, Ahlbom A, Hall P, Feychting M. Long-term mobile phone use and brain tumor risk. Am J Epidemiol 2005;161(6):526-35.

20. Christensen HC, Schuz J, Kosteljanetz M, Poulsen HS, Boice JD Jr., McLaughlin JK, et al. Cellular telephones and risk for brain tumors: a population-based, incident case-control study. Neurology 2005;64(7):1189-95.

21. Schoemaker MJ, Swerdlow AJ, Ahlbom A, Auvinen A, Blaasaas $\mathrm{KG}$, Cardis E, et al. Mobile phone use and risk of acoustic neuroma: results of the Interphone case-control study in five North European countries. Br J Cancer 2005;93(7):842-8.

22. Edwards CG, Schwartzbaum JA, Lonn S, Ahlbom A, Feychting M. Exposure to loud noise and risk of acoustic neuroma. Am J Epidemiol 2006;163(4):327-33. 
23. Lonn S, Ahlbom A, Christensen HC, Johansen C, Schuz J, Edstrom S, et al. Mobile phone use and risk of parotid gland tumor. Am J Epidemiol 2006;164(7):637-43.

24. Takebayashi T, Akiba S, Kikuchi Y, Taki M, Wake K, Watanabe $\mathrm{S}$, et al. Mobile phone use and acoustic neuroma risk in Japan. Occup Environ Med 2006;63(12):802-7.

25. Hepworth SJ, Schoemaker MJ, Muir KR, Swerdlow AJ, van Tongeren MJ, McKinney PA. Mobile phone use and risk of glioma in adults: case-control study. BMJ 2006;332(7546):883-7.

26. Schuz J, Bohler E, Berg G, Schlehofer B, Hettinger I, Schlaefer $\mathrm{K}$, et al (2006) Cellular phones, cordless phones, and the risks of glioma and meningioma (interphone study group, Germany). Am J Epidemiol 2006;163(6):512-20.

27. Schuz J, Bohler E, Schlehofer B, Berg G, Schlaefer K, Hettinger $\mathrm{I}$, et al. Radiofrequency electromagnetic fields emitted from base stations of DECT cordless phones and the risk of glioma and meningioma (Interphone Study Group, Germany). Radiat Res 2006;166(1 Pt 1):116-9.

28. Berg G, Spallek J, Schuz J, Schlehofer B, Bohler E, Schlaefer K, et al. Occupational exposure to radio frequency/microwave radiation and the risk of brain tumors: Interphone Study Group, Germany. Am J Epidemiol 2006;164(6):538-48.

29. Schoemaker MJ, Swerdlow AJ, Hepworth SJ, McKinney PA, van Tongeren M, Muir KR. History of allergies and risk of glioma in adults. Int J Cancer 2006;119(9):2165-72.

30. Schoemaker MJ, Swerdlow AJ, Auvinen A, Christensen HC, Feychting M, Johansen C, et al. Medical history, cigarette smoking and risk of acoustic neuroma: an international casecontrol study. Int J Cancer 2007;120(1):103-10.

31. Lahkola A, Auvinen A, Raitanen J, Schoemaker MJ, Christensen $\mathrm{HC}$, Feychting M, et al. Mobile phone use and risk of glioma in 5 North European countries. Int J Cancer 2007;120(8):1769-75.

32. Schoemaker MJ, Swerdlow AJ, Hepworth SJ, van Tongeren M, Muir KR, McKinney PA. History of allergic disease and risk of meningioma. Am J Epidemiol 2007;165(5):477-85.

33. Klaeboe L, Blaasaas KG, Tynes T. Use of mobile phones in Norway and risk of intracranial tumours. Eur J Cancer Prev 2007;16(2):158-64.

34. Malmer B, Feychting M, Lonn S, Ahlbom A, Henriksson R. p53 Genotypes and risk of glioma and meningioma. Cancer Epidemiol Biomarkers Prev 2005;14(9):2220-3.

35. Schwartzbaum J, Ahlbom A, Malmer B, Lonn S, Brookes AJ, Doss $\mathrm{H}$, et al. Polymorphisms associated with asthma are inversely related to glioblastoma multiforme. Cancer Res 2005;65(14):6459-65.

36. Malmer BS, Feychting M, Lonn S, Lindstrom S, Gronberg H, Ahlbom A, et al. Genetic variation in p53 and ATM haplotypes and risk of glioma and meningioma. $J$ Neurooncol 2007;82(3):229-37.

37. Wigertz A, Lonn S, Mathiesen T, Ahlbom A, Hall P, Feychting M. Risk of brain tumors associated with exposure to exogenous female sex hormones. Am J Epidemiol 2006;164(7):629-36.
38. Larjavaara S, Mäntylä R, Salminen T, Haapasalo H, Raitanen J, Jääskeläinen $\mathrm{J}$, et al. Incidence of gliomas by anatomic location. Neuro-Oncology 2007; Doc. D05-00016.

39. Rothman KJ, Chou C, Morgan R, Balzano Q, Guy AW, Funch $\mathrm{DP}$, et al. Assessment of cellular telephone and other radio frequency exposure for epidemiologic research. Epidemiology 1996;7(3):291-8.

40. Wiart J, Mittra R, Chaillou S, Altman Z. The analysis of human head interaction with a hand-held mobile using the non-uniform FDTD. DOI No.: 10.1109/APWC.1998.730651.

41. Dimbylow PJ, Mann SM. SAR calculations in an anatomically realistic model of the head for mobile communication transceivers at $900 \mathrm{MHz}$ and $1.8 \mathrm{GHz}$. Phys Med Biol 1994;39(10):1537-53.

42. Vrijheid M, Cardis E, Armstrong BK, Auvinen A, Berg G, Blaasaas $\mathrm{KG}$, et al. Validation of short-term recall of mobile phone use for the Interphone Study. Occup Environ Med 2006;63:23743.

43. Messung soziodemographischer Merkmale in der Epidemiologie. Munich, Germany: MMV Medizin Verlag; 1998.

44. Little RJA, Rubin DB. Nonresponse in sample surveys. Statistical analysis with missing data. New York: John Wiley \& Sons Inc.; 1997. p. 50-78.

45. Weinberg CR, Moledor ES, Umbach DM, Sandler DP. Imputation for exposure histories with gaps, under an excess relative risk model. Epidemiology 1996;7(5):490-7.

46. Scientific Committee on Emerging and Newly Identified Health Risks (SCENIHR). Scientific opinion on possible effects of Electromagnetic Fields (EMF) on human health. SCENIHR Accessed: 2007. Available from: URL: http://ec.europa.eu/health/ ph_risk/committees/04_scenihr/docs/scenihr_o_007.pdf

47. Mantiply ED, Pohl KR, Poppell SW, Murphy JA. Summary of measured radiofrequency electric and magnetic fields $(10 \mathrm{kHz}$ to $30 \mathrm{GHz}$ ) in the general and work environment. Bioelectromagnetics 1997;18(8):563-77.

48. Hartge P. Participation in population studies. Epidemiology 2006;17(3):252-4

49. Lahkola A, Salminen T, Auvinen A. Selection bias due to differential participation in a case-control study of mobile phone use and brain tumors. Ann Epidemiol 2005;15(5):321-5.

50. Vrijheid M, Deltour I, Krewski D, Sanchez M, Cardis E. The effects of recall errors and of selection bias in epidemiologic studies of mobile phone use and cancer risk. J Exposure Sci Environ Epidemiol 2006;16(4):371-84.

51. Cardis E, Kilkenny M. International case-control study of cancers of brain and salivary gland - report of the feasibility study. Lyon: International Agency for Research on Cancer (IARC); 1999. Report No.: 99/004

52. Greenland S, Mickey RM. The impact of confounder selection criteria on effect estimation. Am J Epidemiol 1989;130(6):1066. 